\title{
Article
}

\section{Educating tomorrow's workforce for the Fourth Industrial Revolution - The necessary breakthrough mindset and culture of the engineering profession}

\author{
Michael Max Bühler ${ }^{1, *}$, Konrad Nübel ${ }^{2}$ and Thorsten Jelinek ${ }^{3}$ \\ 1 Hochschule Konstanz, Technik, Wirtschaft und Gestaltung; michael.buehler@htwg-konstanz.de \\ 2 Technische Universität München; konrad.nuebel@tum.de \\ 2 DPG GmbH, Berlin; jelinek@dpg-gmbh.com \\ * Correspondence: michael.buehler@htwg-konstanz.de; Tel.: +49 15114314499
}

\begin{abstract}
We are calling for a paradigm shift in engineering education. In times of the Fourth In-

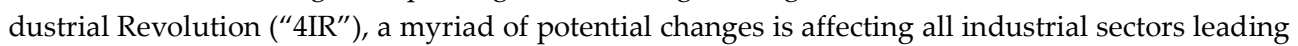
to increased ambiguity that makes it impossible to predict what lies ahead of us. Thus, incremental culture change in education is not an option any more. The vast majority of engineering education and training systems, having remained mostly static and underinvested in for decades, are largely inadequate for the new 4IR labor markets. Some positive developments in changing the direction of the engineering education sector can be observed. Novel approaches of engineering education already deliver distinctive, student centered curricular experiences within an integrated and unified educational approach. We must educate engineering students for a future whose main characteristics are volatility, uncertainty, complexity and ambiguity. Talent and skills gaps across all industries are poised to grow in the years to come. The authors promote an engineering curriculum that combine timeless didactic tradition, such as Socratic inquiry, project-based learning and first-principles thinking with novel elements (e.g. student centered active and e-learning by focusing on the case study and apprenticeship pedagogical methods) as well as a refocused engineering skillset and knowledge. These capabilities reinforce engineering students' perceptions of the world and the subsequent decisions they make. This $4 \mathrm{IR}$ engineering curriculum will prepare engineering students to become curious engineers and excellent communicators better navigating increasingly complex multistakeholder ecosystems.
\end{abstract}

Keywords: engineering education; Forth Industrial Revolution; 4IR; skills gap; future of work; elearning; didactics

\section{Introduction and Background}

We cannot ignore that we have already arrived amid the next industrial revolution that fundamentally transforms our economies, our societies and even who we are as human beings. Thinking and acting around this Fourth Industrial Revolution (4IR) [1] which is characterized by a range of new technologies [2] that are fusing the physical, digital and biological worlds - demand that we acquire new skills and a new style of leadership [3]. With these deep-seated changes impacting us, educational requirements for the engineering profession will be heavily in flux. To successfully meet the environmental, societal and financial challenges of an increasingly complex and hyper-connected world, we must get together to rethink and reinvent our profession. Hence, we must ask ourselves how we can create a more integral engineering curriculum that will anticipate industrial disruption and sufficiently prepare our young as well as established civil engi- 
neers for the future. The 4IR demands that the engineering profession renews itself continuously, better promotes its accomplishments, and cultivates a future generation of engineers. This next generation of engineers must be well equipped to contribute to society, must lead and shape global issues, identify and solve not only technical problems but find, articulate and pursue the societal opportunities of tomorrow. Humankind in the $21^{\text {st }}$ century is faced with numerous global challenges and risks [4], such as failure of climatechange mitigation and adaptation, failure or increasing cyber vulnerability of critical infrastructure, water crises and failure of long-term strategic infrastructure and urban planning. The civil engineering profession needs to bear these challenges and take on more responsibility [5]. A business-as-usual attitude in the face of such cruel challenges will not be the responsible course of action.

\section{Transforming the Engineering Profession}

When asked the top three most critical areas of transformation in civil engineering, during the World Economic Forum's Annual Meeting 2018, Chief Executive Officers of the construction industry ${ }^{1}$ prioritized the key areas as follows: Attracting new talent and building up required skills, integrating and collaborating across the value chain and adopting advanced technologies on a large scale (Figure 1). Similarly, during the Annual Summit of McKinsey's Global Infrastructure Initiative in the fall of 2018, construction executives were asked what the greatest challenges will be for project leaders in the next decade: Developing a culture of innovation that embraces disruptive technologies, attracting and retaining the right talent, moving to more collaborative, less adversarial contractual arrangements and developing a more diverse and inclusive workforce ${ }^{2}$ were the topmost challenges identified.

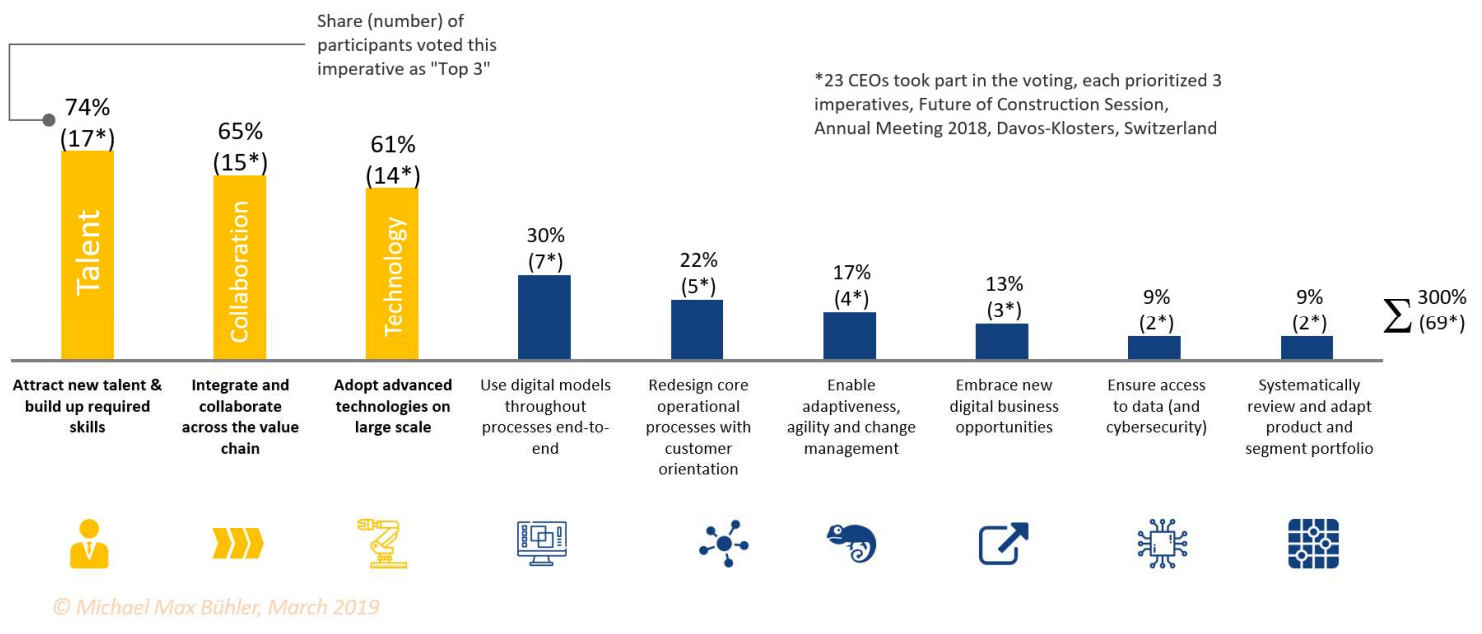

Figure 1: What are the most critical areas of transformation in the construction industry?

\footnotetext{
1 World Economic Forum Annual Meeting 2018: 23 CEOs took part in the voting, each prioritized 3 imperatives: Attract new talent \& build up required skills (74\%); Integrate and collaborate across the value chain (65\%); Adopt advanced technologies on large scale (61\%); Use digital models throughout processes end-to-end (30\%); Redesign core operational processes with customer orientation (22\%); Enable adaptiveness, agility and change management (17\%); Embrace new digital business opportunities (13\%); Ensure access to data and cybersecurity (9\%); Systematically review and adapt product and segment portfolio (9\%). Future of Construction Session, Annual Meeting 2018, Davos-Klosters, Switzerland

2 McKinsey Global Infrastructure Initiative (2018): Survey during the Annual Summit in London, October 2018. Developing a culture of innovation that embraces disruptive technologies (43\%), attracting and retaining the right talent (27\%), moving to more collaborative, less adversarial contractual arrangements (21\%) and developing a more diverse and inclusive workforce (9\%).
} 
Engineering education is not yet sufficiently tailored to foster and train for effective multidisciplinary collaboration to master the 4IR as well as prepare the engineer to lead, negotiate and communicate in an increasingly complex and technology-driven construction ecosystem [6]. While there are an increasing number of multi-disciplinary, user-centred and entrepreneurial curricula that point in the right direction and embrace active project-based learning as well as focusing on rigor in the engineering fundamentals, a paradigm shift is required to fully be able to mitigate today's challenges. As evidence shows, failure to educate for and to establish clear and efficient project-wide collaborative and multi-disciplinary practices can be disastrous:

Most of the capital projects from numerous sectors still struggle to deliver on-time, on-budget and on-scope projects, damaging business performance, reputation and financial sustainability [7]. Over $90 \%$ of mega projects face cost overruns [8], and across all capital project sectors, the cost of claims and commercial disputes is estimated to be approximately $\$ 870$ billion globally [9].

To overcome these major challenges and the lack of collaboration in capital projects, experts and practitioners are increasingly proposing more collaborative contractual and procurement frameworks that ensure success by reducing project complexity, incentivizing risk sharing, and promoting information sharing which is also becoming a key competitive requirement in the age of 4IR. In the United Kingdom for instance, which is now leading globally in developing and implementing collaborative contracting practices, the Latham Report [10] described almost 30 years ago the construction industry as ineffective, adversarial, fragmented and incapable of delivering for its customers, proposing that there should be greater partnering and teamwork. The Egan Report [11], the UK Construction Strategy [12], and the Farmers Review [13] reinforced this message highlighting that society does not get full value from public sector construction, the construction sector under-performs, that there are poor and inconsistent procurement practices leading to waste and inefficiency and that there are low levels of standardisation, and fragmentation of the public-sector client base. There is widespread agreement that collaborative relationships combined with a total-cost-of-ownership approach can deliver superior results, so long as they remain focused on mutual value. There is general agreement that adversarial negotiation and unbalanced risk allocations damage the potential for collaboration and that this, in turn, undermines innovation and realising value. Establishing collaborative practices is of importance on capital projects, as they are likely to involve bringing together a large number of diverse disciplines, many of whom will not have worked together before. They are also likely to involve the coordination and integration of a great deal of complex information, procedures and systems.

\section{Leading a paradigm shift in engineering education}

The First Industrial Revolution used water and steam power to mechanize production. The Second used electric power to create mass production. The Third used electronics and information technology to automate production. Now a Fourth Industrial Revolution is building on the Third, the digital revolution that has been occurring since the middle of the last century. It is characterized by a fusion of technologies that is blurring the lines between the physical, digital, and biological spheres [14]. As a consequence, we must educate engineering students for a future whose main characteristic is ambiguous change. New 4IR technologies will impact what the next generation of engineers need to learn, as well as how they learn [15]. The First Industrial Revolution saw an emergence of work specializations and with it the proliferation of new educational models including the establishment of professional schools and the development of universities (Table 1), as society evolved its accommodation with new technologies and the new economy they produced. It is reasonable to expect something similar this time around, with a whole generation of engineering curricula reformers and ed tech entrepreneurs already experimenting 
with new learning tools and new educational priorities [16] suitable to help inspiring innovators redefine the industry [17]. As shown in a recent report, technology and globalization are already significantly transforming the engineering work [18]. However, engineering education and training systems, having remained mostly static and underinvested in for decades, are largely inadequate for the new 4IR labour markets [19]. We must therefore rethink the way talent is developed and deployed in the world. This will require breaking down old silos between education systems and labour markets, more agile approaches to regulation, new forms of public-private collaboration, and new norms and values [20].

Table 1: Impact of technological change on education paradigm [21]

\begin{tabular}{|c|c|c|c|}
\hline Period & Revolution & Industrial changes & Educational changes \\
\hline $\begin{array}{l}18^{\text {th }} \text { to } 19^{\text {th }} \\
\text { century }\end{array}$ & $\begin{array}{l}\text { 1st indus- } \\
\text { trial revolu- } \\
\text { tion }\end{array}$ & $\begin{array}{l}\text { Invention of steam engine, the } \\
\text { transition from manual labour to } \\
\text { machine }\end{array}$ & $\begin{array}{l}\text { Emergence of work specializations, establish- } \\
\text { ment of professional schools, development of } \\
\text { universities }\end{array}$ \\
\hline $\begin{array}{l}19^{\text {th }}-\text { begin- } \\
\text { ning of } 20^{\text {th }} \\
\text { century }\end{array}$ & $\begin{array}{l}\text { 2nd indus- } \\
\text { trial revolu- } \\
\text { tion }\end{array}$ & $\begin{array}{l}\text { Transition to electricity, devel- } \\
\text { opment of transport, communi- } \\
\text { cations, development of high- } \\
\text { tech industries }\end{array}$ & $\begin{array}{l}\text { Development of multilevel training system for } \\
\text { industry, standardization of education, prestige } \\
\text { growth of engineering education }\end{array}$ \\
\hline $\begin{array}{l}2^{\text {nd }} \text { half of } \\
20^{\text {th }} \text { to begin- } \\
\text { ning of } 21^{\text {st }} \\
\text { century }\end{array}$ & $\begin{array}{l}\text { 3rd indus- } \\
\text { trial revolu- } \\
\text { tion }\end{array}$ & $\begin{array}{l}\text { Transition to telecommunication } \\
\text { technologies, automation of pro- } \\
\text { duction, rapid development of } \\
\text { services }\end{array}$ & $\begin{array}{l}\text { Integration and globalization of education, de- } \\
\text { velopment of academic mobility, transition to } \\
\text { the international educational standards, increase } \\
\text { in training specialists for services }\end{array}$ \\
\hline $\begin{array}{l}\text { Beginning of } \\
21^{\text {st }} \text { century }\end{array}$ & $\begin{array}{l}\text { 4th indus- } \\
\text { trial revolu- } \\
\text { tion }\end{array}$ & $\begin{array}{l}\text { The Internet of things, integra- } \\
\text { tion of "cyber } \\
\text { physical systems", or CPS, in } \\
\text { production processes, neuronet }\end{array}$ & $\begin{array}{l}\text { Individualization and virtualization of educa- } \\
\text { tion, strengthening of project and multidiscipli- } \\
\text { nary nature of engineering education, the devel- } \\
\text { opment of interactive educational resources }\end{array}$ \\
\hline
\end{tabular}

\section{Closing the talent and skills gap in construction}

Skills gaps across all industries are poised to grow in the Fourth Industrial Revolution. Access to skilled workers is already a key factor that sets successful companies apart from failing ones. In an increasingly data-driven future - the European Commission believes there could be as many as around 760,000 unfilled jobs in the European ICT sector by 2020 [22] - this difference will become even more acute. Rapid advances in artificial intelligence (AI), robotics and other emerging technologies are happening in ever shorter cycles, changing the very nature of the jobs that need to be done - and the skills needed to do them - faster than ever before. At least 133 million new roles generated as a result of the new division of labour between humans, machines and algorithms may emerge globally by 2022, according to the World Economic Forum. There will also be strong demand for technical skills like programming and app development, along with skills that computers can't easily master such as creative thinking, problem-solving and negotiating [23].

According to recent studies [24] of the World Economic Forum, in particular the construction industry urgently needs new talent and skills [25] to help in the adoption of new technologies that will foster the sector's transformation to be able to address global challenges such as climate change, resource scarcity, rapid urbanization, the housing crisis 
and the infrastructure gap. The challenges, however, continuously emerge and require every civil engineer to learn in new ways, and to think far beyond traditional boundaries [26].

In the past 50 years, the construction industry did not innovate as quickly as other sectors, resulting in stagnating productivity and negative effects on the economy, society and the environment [27]. A major underlying problem is the fragmented industry where scaling effects are difficult to achieve. Therefore, human resources do not scale with the amount of output, leading to pressure on wages as a means for increasing prices. This leads to ongoing industry-wide shortage of qualified workers. This shortage has undermined project management and execution, adversely affecting cost, timelines and quality. It also has impeded the adoption of new digital technologies, such as building information modelling (BIM) [28], automated equipment and cloud-based collaboration tools, which could improve productivity [27].

To counter the current talent and skills gap, construction companies must strategically plan talent supply and demand, improve in-house learning and development programmes, and adopt new technologies that will advance productivity and job satisfaction. Companies must also update their work culture to appeal to younger workers and become more diverse, including increasing the percentage of women in the industry. Industry organizations should run image campaigns to promote construction jobs, target prospective new pools of talent, such as employees with suitable skills from other industries like gaming, establish common bodies of knowledge, make career paths more transparent, and collaborate on training with academia and vocational training providers. Government must use its role as a regulator and major owner of public works projects to develop regulations and sponsor initiatives that spur innovation and thereby increase the attractiveness of the industry. It must also harmonize building standards to make projects less complex and less labour intensive, update public-sponsored apprenticeships and academic programmes to include trainings on new skills, and boost support for job services [23].
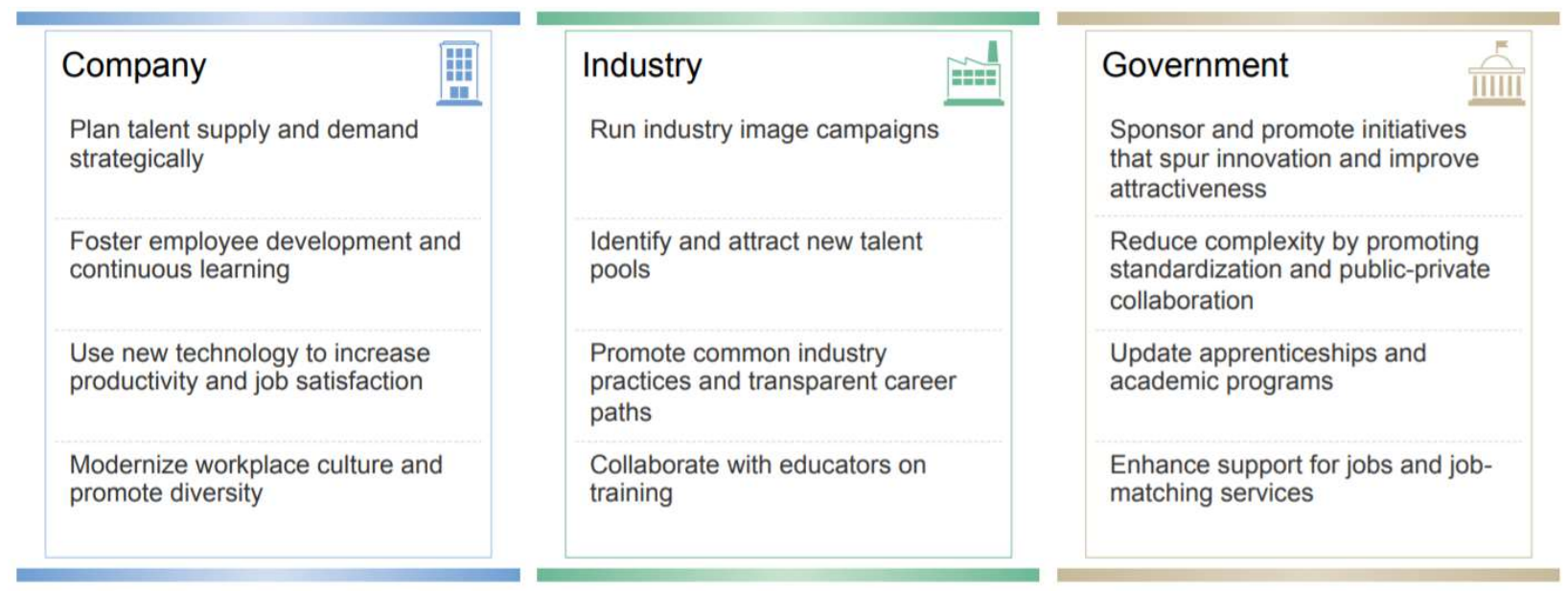

Figure 2: Three pillars to solve the industry's talent and skills gap [25]

The 4IR is transforming the world of work. Technology is advancing faster than humans, disrupting both jobs and the skills needed to compete [29]. Research by McKinsey [30] suggests that globally about half of the jobs performed by humans today will be disrupted by automation, and a survey of business leaders by the World Economic Forum [31] suggests that $42 \%$ of the core job skills required today are set to change substantially by 2022 . The OECD estimates that $14 \%$ of existing jobs could disappear as a result of au- 
tomation in the next $15-20$ years, and another $32 \%$ are likely to change radically as individual tasks are automated [32]. With the Fourth Industrial Revolution advancing, employers are demanding a greater mix of skills [33].

\section{Refocussing on future skills}

A recent Pew Research Center [34] survey of 1,408 technology and education professionals suggested that the most valuable skills in the future will be those that machines can't yet easily replicate, like creativity, critical thinking, emotional intelligence, adaptability and collaboration. In short, people need to learn how to learn, because the only hedge against a fast-changing world is the ability to critically think, understand first principle thinking, adapt and collaborate well.

According to analysis [35] from the world's largest professional-networking site LinkedIn, 2019's employers are looking for a combination of both hard and even more importantly soft skills, with creativity topping the list of desired attributes. According to LinkedIn CEO Jeff Weiner, the biggest skills gap he sees is soft skills. After creativity, the top soft skills were persuasion, collaboration, adaptability and time management. What most employers want, Weiner says, are written communication, oral communication, teambuilding, and leadership skills.

According to a recent World Economic Forum report [36], the Top 10 Skills of 2020 are all soft skills - with people and cognitive skills gaining precedence over others. A reported [37] 57\% of leaders, including Sheryl Sandberg, Chief Operating Officer of Facebook, and Eric Schmidt, Executive Chairman of Google, agree that soft skills are more important than hard skills in job candidates. As technologies like automation and algorithms create new high-quality jobs and wipe out others, demand for such competencies is only likely to increase. The findings chime with the World Economic Forum's Future of Jobs report [38], which concluded that "human" skills like originality, initiative and critical thinking are likely to increase in value as technology and automation advances. The Forum looked at how the desirability of those attributes is likely to evolve over time, with active learning, creativity and social influence climbing up the list. "Strengthening a soft skill is one of the best investments you can make in your career, as they never go out of style," according to LinkedIn Learning Editor, Paul Petrone. "Plus, the rise of AI is only making soft skills increasingly important, as they are precisely the type of skills robots can't automate." The hard skills in demand also reflect the increasingly digital world, with cloud computing and AI coming out on top, with engineers in demand as more and more services and data migrate to the cloud, followed by analytical reasoning, since companies need to make decisions based on the myriad of data that's now accessible to them. People management came fourth, followed by user experience design - the process of making all these new technologies accessible and easy for humans to interact with.

Enlisting and managing talent has long been a challenge for the construction sector. As Brendan Bechtel, chairman and CEO of Bechtel Group, says: "Ours is a people business that depends on fielding the most capable project teams in the world." It's a challenge that's only going to be more pressing in the years ahead - and not solely in construction. A recent World Economic Forum report [25] warns how troublesome coming employment trends might prove: the continuing volatility of workforce demand and composition; the scarcity of skilled labour, driven by demographic shifts; and the demand for new and broader skill sets at all levels, driven by surging technology.

The World Economic Forum [39] has developed a promising model for quality education during the Fourth Industrial Revolution to catalyse systemic change. It identified eight critical characteristics for learning content and learning experiences that define highquality learning, or Education 4.0 (Figure 3). 


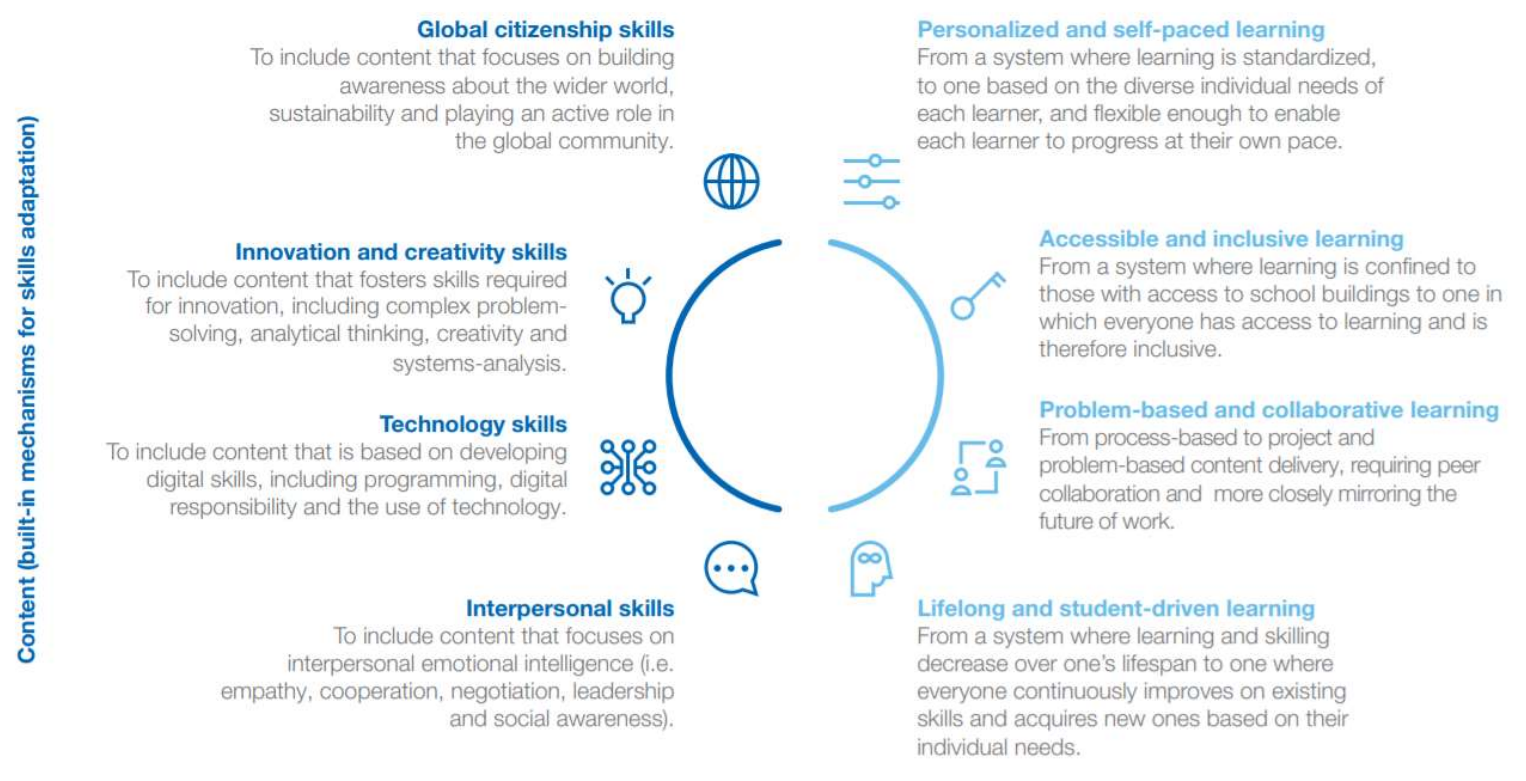

Figure 3: Education 4.0 - A Global Framework for Shifting Learning Content and Experiences Towards the Needs of the Future [39]

In a recent construction-industry survey conducted for the World Economic Forum, with more than 100 respondents, $77 \%$ of respondents agreed that the industry is not doing enough to attract and retain talent, and not one of the respondents fully agreed that the industry is investing enough in recruitment. To keep up, attracting new talent and improving the skills of the existing workforce were deemed priorities by $74 \%$ of industry CEOs at the 2018 World Economic Forum in Davos. Improving integration and collaboration along the value chain $(65 \%)$ and adopting advanced technologies at scale $(61 \%)$ were other key actions they considered.

\section{Adopting novel approaches in engineering education}

Today, thought leaders in engineering education agree collectively that the progress of students' higher-order cognitive and intellectual aptitudes is one of the most vital educational tasks of engineering programs. These capabilities reinforce engineering students' perceptions of the world and the subsequent decisions they make. Specifically, critical thinking ${ }^{3}$ is central to both personal development and societal needs. The capacity of engineering students to master good reasoning to problem solutions can be fostered by a didactic process aimed directly at developing students' critical thinking skills.

According to a recent study on "the global state of the art in engineering education" conducted by the Massachusetts Institute of Technology's (MIT) New Engineering Education Transformation (NEET) initiative, a range of key barriers continue to constrain positive change in engineering education worldwide including but not limited to:

- Misalignment of government and higher education goals,

- Failure to deliver student-centred active learning [40] to large student cohorts,

- Siloed monodisciplinary structure of many engineering schools, and

3 the capacity to probe and evaluate skilfully, analytically and fairly the quality of evidence, formulas, precepts and pieces of received wisdom that too often go unexamined and unchallenged and detect inaccuracies, error, hypocrisy, manipulation, dissembling, and bias 
- Faculty appointment and promotion systems that are not perceived as rewarding teaching achievements [41]

However, some positive developments in changing the direction of the engineering education sector can be observed. In this context, the NEET study identified a set of current and emerging education institutions that demonstrate good educational practices including

- user-centred design,

- technology-driven entrepreneurship,

- active project-based learning, and

- a focus on rigor in the engineering fundamentals.

A group of current ${ }^{4}$ and emerging 5 institutions in engineering education introduced a new generation of engineering programmes, many of which were developed from a blank slate or the product of systemic educational reform, and which were often shaped by competitive pressure as well as specific regional needs and constraints. Distinctive educational features of these leading programmes include work-based learning, multidisciplinary programmes and a dual emphasis on engineering design and student self-reflection. The study suggests that the novel programs have benefitted from strong and visionary academic leadership, a faculty culture of educational innovation and new tools that support educational exploration and student assessment. As a key takeaway of the NEET study, most successful engineering programmes move towards socially relevant and outward-facing engineering curricula. Such curricula emphasize student choice, multidisciplinary learning and societal impact, coupled with a breadth of student experience outside the classroom, outside traditional engineering disciplines and across the world. Novel approaches of engineering education deliver distinctive, student centred curricular experiences within an integrated and unified educational approach. Progressive curricula, for instance of Olin College of Engineering [42] or Iron Range Engineering [43], had been designed from scratch and followed an integral reform approach. Hands-on experiences such as work-based learning and societally relevant design projects are embedded into the programmes in a way that provides a solid platform for student self-reflection and a pathway for students to both contextualize and apply the knowledge and skills they have gained elsewhere in the curriculum. Clearly, a new generation of leaders in engineering education is currently emerging delivering integrated student-centred curricula at scale that include multidisciplinary design projects, which contextualize and integrate learning across courses and years of study. Students are being put at the centre and use the resources to facilitate team projects and authentic experiences, subsequently the taught curriculum is put online. As a result, almost all technical engineering content - including both knowledge and skills - is delivered online and accessed independently by students, as and when they need it. This new approach is described as "completely rethinking what engineering education ought to look like" with the potential to be "very influential, if they can pull it off." [41, 44]

In summary, bold new methodologies that most effectively connect science and technology to real-life situations using active learning pedagogies need to be emphasized

\footnotetext{
4 The five institutions most frequently identified as "current leaders in engineering education" are Massachusetts Institute of Technology (MIT), US;

Olin College, US; Aalborg University, Denmark; TU Delft, Netherlands; and Stanford University, US

5 The ten most frequently identified "emerging leaders" in engineering education are SUTD, Singapore; Olin College, US; UCL, UK; PUC, Chile; Iron Range Engineering, US; NUS, Singapore; TU Delft, Netherlands; Charles Stunt University, Australia; Tsinghua University, China; and Arizona State University, US
} 
more in engineering classrooms. Discussions have revolved around project-based learning, case-based learning, discovery learning, and just-in-time teaching with three instructional approaches of active learning, cooperative learning, and problem-based learning [45]. The benefits of using these progressive approaches are improved retention of knowledge, better reasoning and analytical skills, development of higher-order skills, greater ability to identify relevant issues and recognize multiple perspectives, higher motivation and awareness of non-technical issues. Many of these outcomes are part of the expected attributes of civil engineers outlined by professional bodies [46].
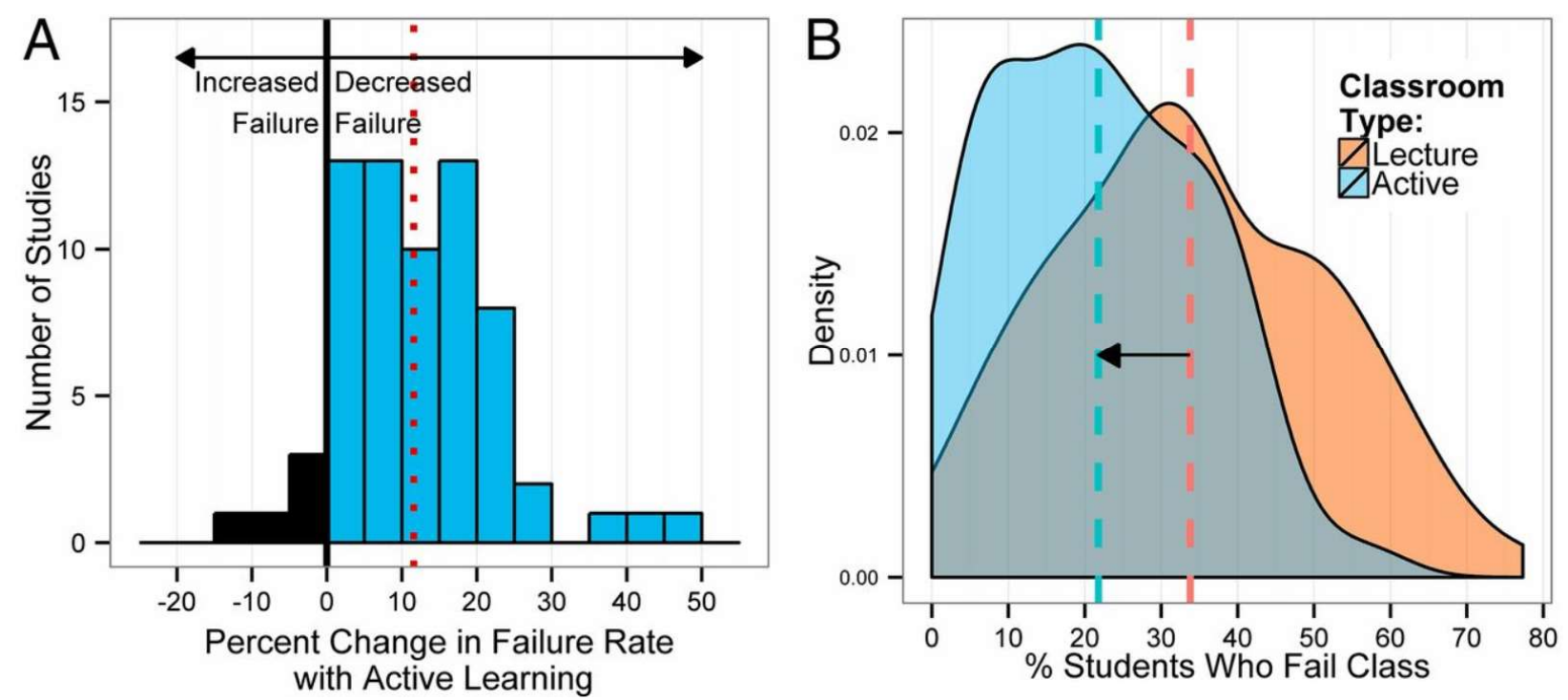

Figure 4: A meta-analysis [47] of 225 studies shows that active learning leads to increases in examination performance, e.g. changes in failure rate. (A) Data plotted as percent change in failure rate in the same course, under active learning versus lecturing. The mean change $(12 \%)$ is indicated by the dashed vertical line. (B) Kernel density plots of failure rates under active learning and under lecturing. The mean failure rates under each classroom type (21.8\% and $33.8 \%)$ are shown by dashed vertical lines.

Learner-centred pedagogies, such as the case method ${ }^{6}$ or Socratic inquiry ${ }^{7}$, hybrid elearning [48] make material more relevant and increases motivation for students [49, 50]. The traditional method of instruction, lecture based, does not appeal to today's scholar and does not provide adequate training as needed for professional development and readiness. A meta-analysis of 225 studies shows that active learning clearly leads to increases in examination performance (Figure 4). The students who encounter material delivered via the case method are more likely to grow and grasp the conceptual understanding of a topic than those who sit through a traditional lecture.

The case method promotes authentic situations and embedded scenarios that the students learn in the confines of the institution further bridging the gap between theory and application. The preparation of the engineering student is achieved by student centred

\footnotetext{
6 The case method is a teaching approach that uses decision-forcing cases to put students in the role of people who were faced with difficult decisions at some point in the past. It developed during the twentieth century from its origins in the casebook method of teaching law pioneered by Harvard legal scholar Christopher C. Langdell. In sharp contrast to many other teaching methods, the case method requires that instructors refrain from providing their own opinions about the decisions in question. Rather, the chief task of instructors who use the case method is asking students to devise and defend solutions to the problems presented by each case.

7 A pedagogical technique in which a teacher does not give information directly but instead asks a series of questions, with the result that the student comes either to the desired knowledge by answering the questions or to a deeper awareness of the limits of knowledge.
} 
active learning by focusing on the case study and apprenticeship pedagogical methods. This will allow us to link technical content with applied knowledge and experiences [51]. Business and engineering case studies have been found to increase students' critical thinking and problem-solving skills, higher-order thinking skills, conceptual change, and their motivation to learn. Results suggest that participants felt the use of case studies was engaging and added a lot of realism to the class making the content more relevant to students. Case-based instruction can be beneficial for students in terms of actively engaging them and allowing them to see the application and/or relevance of engineering to the real world [49]. At St. John's [52], for instance, you will not find 100-person lectures, teaching assistants or multiple-choice tests. Instead, classes are led by tutors who guide students through a Socratic inquiry. Despite its reputation as a merciless exercise in student humiliation, the Socratic method is an interactive form of intellectual sandpapering that smooths out hypotheses and eliminates weak ideas through group discourse. Tutors lead St. John's discussions but rarely dominate; they are more like conversation facilitators, believing that everyone in class is a teacher, everyone a learner [53]. The Socratic inquiry prepares engineering students to become excellent communicators better navigating an increasingly complex construction multistakeholder ecosystem.

The fourth industrial revolution requires the education sector to reform the entire education process and align it more synchronously with future needs so that students can interact smoothly with the revolutionary, exponential changes. In this context, e-learning in particular will play a major role, as networking and thus scalability will create a healthy competition of the best content and the most sophisticated didactics. But also through e-learning collaborations, there are numerous opportunities for educational institutions, especially higher educational institutions, to work, collaborate and help each other within the e-learning platform [54].

\section{Shaping the future of the engineering profession}

The construction industry is at an inflection point, analogous to the move from landline telephony to cellular technology. 4IR technologies are disrupting the industry, providing new opportunities to address the challenges of poor profitability and productivity, project performance, skilled labour shortages, and sustainability concerns. The technological transformation of the construction industry is not a question of if or when the changes are happening now [55]. Today, construction is an ever-evolving industry with numerous trends impacting the methods with which buildings are built and strategies upon which construction companies are managed. Therefore, construction professionals are increasingly charged with understanding these industry trends and converting emerging challenges into capitalized opportunities.

This in turn also requires a paradigm shift in engineering education. For construction educators to properly prepare students with the associated competencies for the advanced work of construction of the future, they must forecast the future and develop curriculum aligned with the projected proficiency requirements. Construction education programs have a growing responsibility of forecasting the necessary competencies for successful future construction professionals and refining academic curriculums to best prepare students for the construction work of the future [56].

The global engineering community is starting to rethink extensively about how to best prepare the engineers of tomorrow. To future proof the profession, civil engineers must be prepared with a broader and deeper vision [57] that embraces the challenges and complexities of the 4IR. As a community, we urgently need to develop a blueprint for shaping the future of the civil engineering profession taking a holistic systems' view. This vision needs to influence how we educate the next generation of engineers as well as how we build, maintain and increase an interactive body of knowledge and methodologies in light of the 4IR with artificial intelligence as a mentor and partner in knowledge generation and dissemination. The role of teachers soon may be passed to virtual tutors. The role 
of gaming environments and augmented reality in educational activities is growing. According to forecasts [58], games and teamwork will become the dominant forms of education and social life by 2035. Another direction of education development is strengthening its project nature, blurring the distinction between traditional technical and humanitarian education. This requires the creation of new interdisciplinary courses, the revision of the classical approaches to engineering and humanitarian education [21]. Rethinking the civil engineering profession will in turn shape the service to society and consequently can enhance the welfare of humanity.

By setting out a bold vision and creating a culture that is undaunted by tradition, Elon Musk and other successful innovators manage to attract the best talent from very different fields and to defy standard industry practice. In contrast, many or most construction companies are characterized by a conservative, "fear of failure" corporate culture and hampered by organizational inertia. Culture is a talent magnet, and construction companies need to implement a corporate culture that challenges the status quo and embraces innovation wholeheartedly. Thus, incremental culture change is not an option any more in the construction industry. The myriad potential changes in the construction industry lead to high ambiguity and make it impossible to predict what lies ahead. By redefining the ultimate frontier, leapfrogging innovations in construction will finally help address major societal challenges, from mass urbanization to climate change. The widespread adoption of game-changing innovations that consider a variety of possible futures is going to make a serious impact, socially, economically and environmentally.

Funding: This research received no external funding

Conflicts of Interest: The authors declare no conflict of interest.

\section{References}

1. Schwab, K., The Fourth Industrial Revolution. 2017: Penguin Books Limited.

2. Buehler, M., Buffet, R., Castagnino, S., The Fourth Industrial Revolution is about to hit the construction industry. Here's how it can thrive. 2018: World Economic Forum Agenda.

3. Buehler, M.M., Reinventing leadership -10 imperative leadership aptitudes you will need as a systemic leader. 2016: World Economic Forum Agenda.

4. Forum, W.E., Global Risk Report 2019. 2019: http://www3.weforum.org/docs/WEF Global Risks Report 2019.pdf.

5. Russell, J.S., Shaping the Future of the Civil Engineering Profession. Journal of Construction Engineering and Management, 2013. 139(6): p. 654-664.

6. Russell, J.S., et al., Education in construction engineering and management built on tradition: Blueprint for tomorrow. Journal of Construction Engineering and Management, 2007. 133(9): p. 661-668.

7. Detrick, H., What You Need to Know About the Collapse of Carillion, a U.K. Construction Giant, in Yahoo Finance. 2018.

8. McK, Voices on Infrastructure: Transforming project delivery, G.I. Initiative, Editor. 2017.

9. Reform, I.f.L., International Comparisons of Litigation Costs in Canada, Europe, Japan, and the United States 2013: http://www.instituteforlegalreform.com/uploads/sites/1/ILR_NERA_Study_International_Liability_Costs-update.pdf.

10. Latham Sir, M., Constructing the team: Final report of the government/industry review of procurement and contractual arrangements in the UK construction industry. 1994, HMSO, London.

11. Department of the Environment, T. and L. the Regions, Rethinking construction The report of the Construction Task Force to the Deputy Prime Minister, John Prescott, on the scope for improving the quality and efficiency of UK construction. 1998. 
U.C.,

$U K$

Government

Office

Construction

Strategy.

2011:

https://assets.publishing.service.gov.uk/government/uploads/system/uploads/attachment data/file/61152/GovernmentConstruction-Strategy_0.pdf.

13. Farmer, M., The Farmer Review of the UK construction labour model "Modernize or die - Time to decide the industry's future", T.C.L. Council, Editor. 2016: http://www.constructionleadershipcouncil.co.uk/wp-content/uploads/2016/10/Farmer-Review.pdf.

14. Schwab, K., The Fourth Industrial Revolution: what it means, how to respond. , in World Economic Forum Agenda. 2016: https://www.weforum.org/agenda/2016/01/the-fourth-industrial-revolution-what-it-means-and-how-to-respond/.

15. Auer, M.E., H. Hortsch, and P. Sethakul, The Impact of the 4th Industrial Revolution on Engineering Education: Proceedings of the 22nd International Conference on Interactive Collaborative Learning (ICL2019) - Volume 2. 2020: Springer International Publishing.

16. Engtoft-Larsen, A.M., Education for the Fourth Industrial Revolution, in World Economic Forum Agenda Podcast. 2018: https://www.weforum.org/agenda/2018/01/podcast-education-for-the-fourth-industrial-revolution/.

17. Willige, A., Six buildings that are revolutionizing the construction industry, in World Economic Forum Agenda. 2017: https://www.weforum.org/agenda/2017/03/buildings-construction-industry-innovation/.

18. WEF, Shaping the Future of Construction - Inspiring Innovators redefine the Industry, W.E. Forum, Editor. 2017: http://www3.weforum.org/docs/WEF Shaping the Future of Construction Inspiring Innovators redefine the industry 2017.pdf.

19. WEF, Realizing Human Potential in the Fourth Industrial Revolution - An Agenda for Leaders to Shape the Future of Education, Gender and Work, in World Economic Forum White Paper. 2017: http://www3.weforum.org/docs/WEF_EGW_Whitepaper.pdf. WEF. Shaping the Future of Gender, Education and Work, System Initiative 2019. 2019.

21. Sakhapov, R. and S. Absalyamova, Fourth industrial revolution and the paradigm change in engineering education. MATEC Web of Conferences, 2018. 245: p. 12003.

22. Hüsing, T.W.B.K.E.D., e-Skills in Europe - Trends and Forecasts for the European ICT Professional and Digital Leadership Labour Markets $\quad$ (2015-2020). 2015: $\quad$ http://eskills-lead.eu/fileadmin/lead/brochure-lead/working paper supply_demand_forecast_2015_a.pdf.

23. Milano, M., The digital skills gap is widening fast. Here's how to bridge it, in World Economic Forum Agenda, W.E. Forum, Editor. 2019: https://www.weforum.org/agenda/2019/03/the-digital-skills-gap-is-widening-fast-heres-how-to-bridge-it/.

24. FOC. Future of Construction: A central platform to exchange best practices and ideas guiding the infrastructure and urban development industry in its transformation and helping it to address its key challenges. 2019.

25. WEF, Shaping the Future of Construction - An Action Plan to solve the Industry's Talent Gap

W.E. Forum, Editor. 2018: http://www3.weforum.org/docs/WEF Action plan to solve the industrys talent gap.pdf.

26. ASCE, A Vision for the Future of Structural Engineering and Structural Engineers: A case for change, in A Board of Governors Task Committee Paper, S.S.E. Institute, Editor. 2013: https://www.asce.org/uploadedFiles/visionforthefuture.pdf.

27. WEF. Shaping the future of construction: A breakthrough in mindset and technology. in World Economic Forum. 2016.

28. WEF, Shaping the Future of Construction - An Action Plan to Accelerate Building Information Modeling (BIM) Adoption, W.E. Forum, Editor. 2018.

29. Glassberg-Sands, E.B., Vinod, Who is first (and last) in the race to build a workforce fit for the future?, in World Economic Forum Agenda, WEF, Editor. 2019: https://www.weforum.org/agenda/2019/07/skills-development-economy-coursera-index/.

30. Chui, M., J. Manyika, and M. Miremadi, The countries most (and least) likely to be affected by automation. Harvard Business Review, 2017. 12.

31. WEF, Strategies for the New Economy: Skills as the Currency of Labour Market, W.E. Forum, Editor. 2019: http://www3.weforum.org/docs/WEF 2019 Strategies for the New Economy Skills.pdf. 
32. OECD, The Future of Work, in OECD Employment Outlook 2019, P. OECD Publishing, Editor. 2019: https://doi.org/10.1787/9ee00155-en.

33. Rahmat, A.M., A.H. Mohd Adnan, and N.M. Mohtar. Industry 4.0 skillsets and 'career readiness': Can Malaysian university students face the future of work? in Proceedings of the International Invention, Innovative \& Creative (InIIC) Conference, Series. 2019.

34. Rainie, L.A., Janna The Future of Jobs and Jobs Training, P.R. Center, Editor. 2018: https://www.pewresearch.org/internet/2017/05/03/the-future-of-jobs-and-jobs-training/.

35. LinkedIn, The Skills Companies need the most in 2019 in LinkedIn Blog. 2019: https://learning.linkedin.com/blog/top-skills/theskills-companies-need-most-in-2019--and-how-to-learn-them.

36. WEF, The Future of Jobs - Employment, Skills and Workforce Strategy for the Fourth Industrial Revolution, in Global Challenge Insight Report, W.E. Forum, Editor. 2016: http://www3.weforum.org/docs/WEF Future of Jobs.pdf.

37. Huppert, M., 3 Business Leaders Share the Most Important Soft Skills They Look for in a New Hire, in LinkedIn Talent Blog. 2017: https://www.linkedin.com/business/talent/blog/talent-acquisition/business-leaders-share-the-most-important-soft-skillsthey-look-for.

38. WEF, The Future of Jobs Report 2018, in Insight Report. 2018: http://www3.weforum.org/docs/WEF_Future_of_Jobs_2018.pdf.

39. WEF, Schools of the Future - Defining New Models of Education for the Fourth Industrial Revolution in Platform for Shaping the Future of the New Economy and Society, W.E. Forum, Editor. 2020: http://www3.weforum.org/docs/WEF Schools of the Future Report 2019.pdf.

40. Wieman, C., Improving How Universities Teach Science: Lessons from the Science Education Initiative. 2017: Harvard University Press.

41. Graham, R., The global state of the art in engineering education. Massachusetts Institute of Technology (MIT) Report, Massachusetts, USA, 2018.

42. $\quad$ Engineering, O.C.o. About Olin. 2021.

43. Engineering, I.R. Iron Range Engineering: Our Model. 2021.

44. Das, S., D. Kleinke, and D. Pistrui. Reimagining Engineering Education: Does Industry 4.0 Need Education 4.0? : ASEE Conferences.

45. Boylan-Ashraf, P.C.S.A.F.M.C.S., A Case for a Reform in Teaching Introductory, Fundamental Engineering Mechanics Courses. Agricultural and Biosystems Engineering, 2014.

46. Newson, T.D., Norbert, Case methods in civil engineering teaching. Canadian Journal of Civil Engineering, 2011. 38(9): p. 10161030 .

47. Freeman, S., et al., Active learning increases student performance in science, engineering, and mathematics. Proceedings of the National Academy of Sciences, 2014. 111(23): p. 8410-8415.

48. Syam, H., et al., Hybrid e-Learning in Industrial Revolution 4.0 for Indonesia Higher Education. International Journal on Advanced Science, Engineering and Information Technology, 2019. 9(4): p. 1183.

49. Yadav, A., G.M. Shaver, and P. Meckl, Lessons Learned: Implementing the Case Teaching Method in a Mechanical Engineering Course. Journal of Engineering Education, 2010. 99(1): p. 55-69.

50. Yadav, A., et al., Case-based instruction: Improving students' conceptual understanding through cases in a mechanical engineering course. Journal of Research in Science Teaching, 2014. 51(5): p. 659-677.

51. Fulk, B., S. Ghahari, and M. Hastak. Case study and apprenticeship pedagogy for training construction engineering students. IEEE.

52. Paterson, J., St. John's College teaching students to 'learn how to learn', in HigherEd Dive. 2018.

53. Marber, P., The most forward-thinking, future-proof college in America teaches every student the exact same stuff, in Quarz Blog. 2017.

54. Azhari, B., et al. E-Learning as connector among education institution in the 4th industrial revolution. in Journal of Physics: Conference Series. 2020. IOP Publishing. 
55. Leeds, R., Top 4 Challenges Facing The Construction Industry, in Future of Construction Blog. 2017.

56. Becker, T.C., E.J. Jaselskis, and C.P. McDermott. Implications of construction industry trends on the educational requirements for future construction professionals. in Proceedings of the associated schools of construction 2011 international conference, Omaha, NE. 2011.

57. Forum, W.E., Infrastructure and Urban Development Industry Vision 2050, in World Economic Forum Industry Agenda. 2018.

58. Luksha, P. and D. Peskov, Global Education Futures: Agenda. 2019: iUniverse. 